\title{
CORPO E ALMA EM UNIDADE: A CONCEPÇÃO WITTGENSTEINIANA DE SER HUMANO
}

\author{
Marcelo Ferreira Ribas ${ }^{1}$ \\ Universidade Estadual de Londrina (UEL) \\ https://orcid.org/0000-0002-5477-375X \\ E-mail: marceloferreiraribas@hotmail.com
}

\section{RESUMO:}

A partir de uma concepção de filosofia que rompe com a tradição filosófica, Wittgenstein apresenta uma perspectiva de ser humano que supera a clássica dicotomia entre corpo e alma, legada pela Modernidade, ao pensalo como um todo integrado, uma unidade psicofísica. Esse entendimento é possível graças à compreensão de filosofia como atividade, e não como teoria. Em um primeiro momento, o filósofo compreendeu que essa atividade se resumia à análise lógica da linguagem; contudo, considerando a abordagem insuficiente para dissolver os problemas filosóficos, gradualmente passa a adotar a análise gramatical da linguagem ordinária, que se volta aos usos das expressões linguísticas, a fim de identificar as regras que orientam o uso das palavras com significado. E assim, atento às práticas linguísticas, entende que o ser humano não se encontra dividido em partes, mas, ao contrário, que corpo e alma constituem uma única realidade. $O$ que é interno ao sujeito (a alma), torna-se visível pelo externo (o corpo) a partir de seu comportamento no mundo, e é assim que o ser humano pode ser compreendido segundo Wittgenstein. Considerando que a concepção wittgensteiniana de ser humano é desdobramento do seu conceito de filosofia, o artigo apresenta, primeiramente, o desenvolvimento da sua compreensão de filosofia para, em seguida, detalhar o conceito de ser humano que se constitui e se faz entender por meio da própria linguagem.

PALAVRAS-CHAVE: Gramática; Ser Humano; Unidade Psicofísica.

\section{BODY AND SOUL IN UNITY: THE WITTGENSTEINIAN CONCEPTION OF HUMAN BEING}

\begin{abstract}
:
From a conception of philosophy that breaks with the philosophical tradition, Wittgenstein presents a human being perspective that surpasses the classic dichotomy between body and soul, legacy by Modernity, when thinking of it as an integrated whole, a psychophysical unit. This understanding is possible thanks to the understanding of philosophy as an activity and not as a theory. At first, the philosopher understood that this activity was limited to the logical analysis of language; however, considering the insufficient approach to dissolve philosophical problems, he gradually adopts the grammatical analysis of ordinary language, which turns to the uses of linguistic expressions, in order to identify the rules that guide the use of words with meaning. And so, attentive to linguistic practices, he understands that the human being is not divided into parts, but, on the contrary, that body and soul constitute a single reality. What is internal to the subject (the soul) becomes visible through the external (the body) from its behavior in the world, and this is how the human being can be understood according to Wittgenstein. Considering that the Wittgensteinian conception of human being is an offshoot of his concept of philosophy, the article first presents the development of his understanding of philosophy to then detail the concept of human being that constitutes and is understood through the language itself.
\end{abstract}

KEYWORDS: Grammar; Human Being; Psychophysical Unit.

\footnotetext{
${ }^{1}$ Doutorando(a) em Filosofia na Universidade Estadual de Londrina (UEL), Londrina - PR, Brasil.
} 


\section{Considerações iniciais}

A partir da investigação sobre a linguagem, o pensamento de Wittgenstein apresenta significativas contribuições para as reflexões de cunho antropológico, cultural, ético, estético, religioso, psicológico, entre outras áreas de interesse filosófico, que seguem interligados pela sua singular concepção de filosofia. É por essa razão que se pretende realizar aqui uma breve exposição sobre o ser humano a partir do pensamento wittgensteiniano.

Parte-se, para tanto, de sua concepção de filosofia, que denota um aspecto importante de continuidade da sua filosofia. Pensada como atividade, primeiro como análise lógica, depois como análise gramatical, em todo caso jamais como uma teoria, o filósofo, finalmente, empreende uma pesquisa que visa esclarecer os diversos termos da linguagem ordinária em busca da compreensão de seus significados.

Em seguida, a partir de sua investigação gramatical de termos psicológicos, Wittgenstein traz a luz a sua concepção de ser humano, não como dividido entre corpo e alma, mas como unidade entre ambos. É como tal que o sujeito se constitui, apresenta-se e é reconhecido no mundo, como se verá a seguir.

\section{A concepção wittgensteiniana de filosofia como atividade: da análise lógica à análise gramatical}

Pensar no conceito wittgensteiniano de filosofia implica no reconhecimento de uma ruptura radical com uma certa maneira tradicional de se conceber a filosofia e o proceder filosófico. Wittgenstein não se contrapõe a um ou outro filósofo em particular (embora, por vezes, é possível identificar autores específicos), mas a toda uma tradição que fez da filosofia a busca pela verdade última de todas as coisas, de Deus, da origem do universo, do homem e da sociedade, bem como dos seus fins últimos, até as condições de possibilidade do conhecimento da realidade. Esse vasto horizonte de investigação produziu muitas teorias e métodos conflitantes entre si, cada qual se investindo na pretensa posição de apresentar a solução verdadeira e definitiva dos problemas filosóficos, em detrimento das demais propostas. Por conta desses conflitos, nunca foi possível elaborar um corpo unitário do pensamento filosófico que propiciasse o progresso de suas investigações, tal como se verifica com o conhecimento científico. Basta um rápido olhar para a história do pensamento, dos primórdios até a atualidade, para se compreender que a filosofia não se apresenta como um conhecimento coeso; ao contrário, o que existe é a multiplicidade de filosofias que se esforçam em se apresentar como sendo a compreensão mais racional e coerente da realidade. E nisso, em vez de resolver problemas, a filosofia acaba por criar outros tantos, em um movimento que parece não haver fim.

Ciente desses percalços, Wittgenstein não tomou partido dos debates filosóficos legados pela tradição para afirmar uma ou outra posição como sendo a verdadeira, mas, antes, procurou "revelar os pontos de contato entre as partes em disputa, os pressupostos compartilhados, assumidos por todos sem discussão, e pô-los em xeque" (HACKER, 2000, p. 11). E um ponto em comum que ele observou nas diferentes filosofias pode ser resumido na constatação constante no parágrafo 255 de Investigações Filosóficas: "O filósofo trata uma questão como uma doença" (WITTGENSTEIN, 1999, p. 100). O problema, ainda mais profundo, não está naquilo que diz esta ou aquela teoria, mas na estrutura de pensamento que lhes é comum e que ele considerava doentia, o conceito de filosofia que lhe pareceu estar na origem dessas dificuldades e que precisava ser devidamente tratado.

Mas por que teria ele utilizado a analogia da doença? Aqui se expressa, em síntese, a posição crítica de Wittgenstein com relação à tradição filosófica, no sentido que, em toda parte, busca-se exaustivamente teorizar o que não pode ser teorizado. Há uma tendência que, para ele, é sinal de enfermidade, que consiste em se colocar problemas e buscar supostas soluções, porém, 
sem perspectiva alguma de encontrar uma resposta definitiva, já que não são passíveis de verificação, o que acaba por gerar outros pontos de vista discordantes para o mesmo problema. É por isso que os filósofos padecem de problemas filosóficos, são atormentados por eles, tal como o enfermo sofre com uma determinada doença. Diante desse quadro, impõe-se a busca de um remédio eficaz para o tratamento das enfermidades do pensamento, porém, a solução não pode ser a proposição de outro problema filosófico, pois assim, estender-se-iam os tormentos, causando novas doenças para as quais não se vislumbra cura. Portanto, outra deve ser a cura para a filosofia.

A comparação entre ciência e filosofia, nesse ponto, torna-se inevitável. Enquanto a ciência se desenvolve a partir de teorias que são verificáveis empiricamente, o mesmo não ocorre com a filosofia, pois nela não há nada que possa ser testado. Na ciência, uma hipótese que não passa pelo crivo da verificação da experiência é descartada e as que passam, servem de apoio para avançar nas pesquisas e seguir adiante. Graças a essa dinâmica, as ciências formam um corpo organizado de conhecimentos, que progride à medida que se consegue solucionar os seus problemas. A filosofia, por sua vez, não funciona dessa maneira, pois as suas teses não podem ser experimentadas para se pôr em prova a falseabilidade ou a veracidade das mesmas. Por isso, ela não progride, mas fica estacionada em meio aos inúmeros debates de opiniões, cumulando mais problemas do que soluções propriamente ditas.

É por isso que, para Wittgenstein, a filosofia não é uma teoria, mas é uma atividade que visa pôr fim aos problemas filosóficos mediante o esclarecimento do funcionamento da linguagem, cuja incompreensão é entendida por ele como a causa dos equívocos e dificuldades que se acumularam ao longo da história do pensamento. A concepção de filosofia como atividade é a terapia que ele propõe para curar a filosofia de suas enfermidades e, assim trazer um pouco de paz à mente inquieta do filósofo.

Embora a referência à doença que precisa de tratamento tenha aparecido apenas nos seus escritos tardios, a busca por uma saída dos problemas filosóficos sempre foi uma preocupação de Wittgenstein e, por isso, a analogia faz sentido para caracterizar todo o seu trabalho filosófico. $O$ conceito de filosofia como atividade mantém-se constante durante o seu itinerário filosófico, das primeiras pesquisas até suas últimas investigações, embora, no curso do desenvolvimento do seu pensamento, tenha havido uma mudança significativa de perspectiva, que vale a pena ser repassada. Mais precisamente, o conceito de filosofia como atividade muda com a passagem do primeiro para o segundo Wittgenstein. Os estudiosos da sua filosofia costumam dividir o autor em dois períodos, sendo o primeiro, relacionado ao horizonte do Tractatus Logico-Philosophicus (publicado em 1921) e, o segundo, relativo às pesquisas desenvolvidas a partir de 1929, das quais Investigações Filosóficas (publicação póstuma de 1953) constitui um marco. Cumpre, portanto, abordá-las separadamente para identificar, em cada fase, o significado assumido por esse conceito.

No primeiro Wittgenstein, o projeto do Tractatus Logico-Philosophicus (doravante TLP) tem por objetivo resolver problemas filosóficos por meio da análise lógica da linguagem ${ }^{2}$. Segundo alega o autor, em geral, os filósofos não compreenderam corretamente como funciona a lógica da linguagem e, por isso, disseram coisas que não poderiam ter sido ditas com sentido, criando, assim, sempre novos e infindáveis embaraços filosóficos. Consequentemente, a exposição do funcionamento lógico da linguagem, de modo correto, resulta naquilo que Wittgenstein chama como sendo o sentido de sua obra: "Poder-se-ia talvez apanhar todo o sentido do livro com estas palavras: o que se pode em geral dizer, pode-se dizer claramente; e sobre aquilo de que não se pode falar, deve-se calar" (WITTGENSTEIN, 2017, p. 125).

Mas o que se pode efetivamente dizer e, por extensão, o que não se pode dizer, devendo-se calar? A questão diz respeito aos limites do próprio pensamento ou, mais precisamente, das

\footnotetext{
${ }^{2}$ No prefácio, Wittgenstein afirma: "O livro trata dos problemas filosóficos e mostra - creio eu - que a formulação desses problemas repousa sobre o mal entendimento da lógica da nossa linguagem" (WITTGENSTEIN, 2017, p. 125).
} 
expressões do pensamento, que somente podem ser traçados por meio da linguagem. Aquilo que respeita tais limites é dito com sentido, e o que os extrapola, é contrassenso, e é exatamente de contrassensos que tratam os filósofos.

A análise lógica, que impõe os limites do que pode ser dito, revela que a linguagem e o mundo compartilham de uma mesma forma lógica, estando, por isso, intimamente conectados. O mundo é tudo que é o caso (TLP 1), ou seja, é logicamente estruturado pela totalidade dos fatos (TLP 1.1); por sua vez, os fatos são estados de coisas (TLP 2); finalmente, os estados de coisas são ligações entre objetos (TLP 2.01), que são simples. Esse mundo é figurado pela linguagem (TLP 2.1) e, aqui, entra o conceito de figuração como representação da realidade do mundo, como consta no TLP 2.11: "A figuração representa a situação no espaço lógico, a existência e inexistência de estados de coisas" (WITTGENSTEIN, 2017, p. 135). Há uma estrita correspondência entre os elementos que compõem o mundo e os elementos que compõem a linguagem, sendo que estes representam aqueles na linguagem, como reflexo da realidade no espelho. Mas para que isso ocorra, é necessário que a figuração tenha algo em comum com o figurado, que é a forma de afiguração (TLP 2.17) com a qual o objeto figurado é representado correta ou incorretamente.

A forma de afiguração é a forma lógica (TLP 2.18), que é a forma da realidade refletida na linguagem, que revela o seu sentido conforme a concordância ou a discordância com a realidade. É por isso que, no TLP 3: "A figuração lógica dos fatos é o pensamento" (WITTGENSTEIN, 2017, p. 139). O pensamento é expresso pela proposição (TLP 3.1), que articula palavras para exprimir sentido, isto é, os fatos do mundo. A proposição mais simples, que Wittgenstein chama de proposição elementar, afirma a existência de um estado de coisas (TLP 4.21). O menor dos elementos da linguagem é o nome que, na proposição, substitui os objetos do mundo (TLP 3.22).

Assim, segundo a teoria da figuração do primeiro Wittgenstein, a estrutura lógica do mundo fica assim designada, do maior para o menor de seus elementos: fatos, estados de coisas, objetos simples. Por sua vez, tem-se a seguinte estrutura lógica da linguagem: proposições (complexas), proposições elementares (simples) e nomes. Pela figuração, ou forma lógica de que compartilham, mundo e linguagem se entrelaçam: os fatos são representados pelas proposições mais complexas, os estados de coisas, pelas proposições elementares e, os objetos simples, pelos nomes. É sob essa relação que se assenta o sentido do que se diz, podendo ser verdadeiro ou falso conforme representa ou não a realidade.

Traçada as condições de possibilidade de um discurso com sentido segundo a análise lógica da linguagem, no $T L P$ 4.003, Wittgenstein chega a seguinte constatação com relação ao estado da arte da filosofia:

\footnotetext{
A maioria das proposições e questões que se formularam sobre temas filosóficos não são falsas, mas contrassensos. Por isso não podemos de modo algum responder a questões dessa espécie, mas apenas estabelecer o seu caráter de contrassenso. A maioria das questões e proposições dos filósofos provém de não entendermos a lógica da nossa linguagem.

(São da mesma espécie que a questão de saber se o bem é mais ou menos idêntico do que o belo) (WITTGENSTEIN, 2017, p. 155).
}

A constatação de Wittgenstein é coerente com o desenvolvido até então. Considerando que as proposições são confirmadas ou falseadas pela verificação da existência das situações de coisas que figuram, e considerando que, nesse sentido, as sentenças filosóficas não representam o mundo e, portanto, não podem ser verificadas, logo, não é possível sequer aferir a verdade ou a falsidade das teorias filosóficas, justamente, pela falta de referência lógica à realidade. Para os problemas filosóficos, simplesmente, não há respostas logicamente válidas. Resta, portanto, a 
conclusão de que se tratam de meros contrassensos, isto é, de que suas expressões são pseudoproposições que atentam contra os limites lógicos da linguagem.

Se tudo o que a filosofia tentou dizer não passa de contrassenso, o que lhe resta, então? A resposta está no TLP 4.112:

O fim da filosofia é o esclarecimento lógico dos pensamentos.

A filosofia não é uma teoria, mas uma atividade.

Uma obra filosófica consiste essencialmente em elucidações.

O resultado da filosofia não são "proposições filosóficas", mas é tornar proposições claras.

Cumpre à filosofia tornar claros e delimitar precisamente os pensamentos, antes como que turvos e indistintos (WITTGENSTEIN, 2017, p. 167).

Essa passagem explicita claramente o significado de filosofia como atividade para Wittgenstein. Não se trata, obviamente, de uma atividade qualquer, mas de uma atividade de esclarecimento dos pensamentos por meio da análise lógica da linguagem, o que é de suma importância. Ela se atém à tarefa de elucidar proposições, porém, as verdadeiras proposições, aquelas que são dotadas de sentido porque figuram o mundo. A filosofia não deve propor teorias, pois as "proposições filosóficas" não são sequer proposições, mas pseudoproposições, que são contrassensos. O TPL 6.53 complementa:

O método correto da filosofia seria propriamente este: nada dizer senão o que se pode dizer; portanto, proposições da ciência natural - ou seja, algo que nada tem a ver com a filosofia; e então, sempre que alguém pretendesse dizer algo de metafísico, mostrar-lhe que não conferiu significado a certos sinais em suas proposições. Esse método seria, para ele, insatisfatório - não teria a sensação de que lhe estivéssemos ensinando filosofia; mas esse seria o único rigorosamente correto (WITTGENSTEIN, 2017, p. 261).

A filosofia, enquanto atividade de esclarecimento lógico da linguagem, volta-se àquilo que se pode dizer com sentido, que são as proposições da ciência natural. Esse seria o único método correto para Wittgenstein, reconhecendo que, para questões metafísicas, possa parecer insatisfatório porque problemas desse tipo são radicalmente desfeitos enquanto verdadeiros problemas por não possuírem sentido algum (faltam-lhes o significado, que é dado exclusivamente pela figuração do mundo na linguagem).

Wittgenstein, contudo, não despreza os problemas da filosofia, como a princípio, se pode intuir a partir de sua posição. Na realidade, as questões filosóficas relativas à ética, à estética, à religião, entre outros, são realmente importantes, porém, não podem ser solucionadas, tal como ocorre com as ciências naturais, porque simplesmente não há tese filosófica que possa ser verificada no mundo, o que garantiria o seu sentido. $O$ filósofo parte de um princípio básico, que consta no TLP 6.5: "Para uma resposta que não se pode formular, tampouco se pode formular a questão. $O$ enigma não existe. Se uma questão se pode em geral levantar, a ela também se pode responder" (WITTGENSTEIN, 2017, p. 261). Em outras palavras, para cada pergunta, deve haver uma resposta logicamente possível, podendo ela ser verdadeira ou falsa; não havendo respostas, como os problemas filosóficos sugerem, então, eles não podem ser sequer considerados como verdadeiras questões. Assim, a solução desses problemas, dada pela filosofia como atividade de esclarecimento, é o seu completo desaparecimento, por simplesmente não resistirem à análise lógica da linguagem.

O que Wittgenstein entende que os problemas filosóficos expressam é, na verdade, o domínio do indizível, que ele chama de Místico, como consta no TPL 6.522: "Há por certo o inefável. Isso se mostra, é o Místico" (WITTGENSTEIN, 2017, p. 261). É nessa região do pensamento (aqui, tomado em uma acepção ampla do termo, não estritamente tractariana, já que para o filósofo não se pode pensar nada de ilógico, segundo TPL 3.03), que se localiza muito 
daquilo que uma concepção tradicional de filosofia produziu ao longo dos séculos, isto é, as teorias a respeito dos mais diversos problemas da vida, como a ética, a estética e a religião, inclusive, quanto à natureza humana, todos discursos reputados como contrassensos e, portanto, inexprimíveis por estarem além dos limites lógicos das expressões do pensamento.

Posteriormente, a partir de 1929, o pensamento de Wittgenstein passa para um período de transição que resulta em um novo olhar a respeito da filosofia, dando origem à fase comumente denominada de segundo Wittgenstein. No contexto das Investigações Filosóficas (doravante $I F$ ), a filosofia segue sendo uma atividade que, inclusive, visa alcançar o esclarecimento conceitual. Todavia, a análise da linguagem por ela empregada não é mais lógica, mas gramatical, sendo essa uma significativa mudança desse período.

No prefácio dessa obra, o filósofo confidencia que desejara publicar juntos "[...] aqueles velhos pensamentos e os novos, pois estes apenas poderiam ser verdadeiramente compreendidos por sua oposição ao meu velho modo de pensar, tendo-o como pano de fundo" (WITTGENSTEIN, 1999, p. 26). Esse trecho é realmente interessante para entender, por um lado, a continuidade do seu trabalho filosófico e, por outro, a visível oposição entre modos de pensar, o antigo em relação ao novo, sendo este melhor compreendido justamente por ter aquele como pano de fundo.

Assim, considerando que o velho modo de pensar propunha que a atividade filosófica se detivesse na análise lógica das proposições empíricas para elucidar o seu sentido, o novo, por sua vez, propõe que a análise da gramática da linguagem ordinária. O que configura tal atividade como gramatical é o empenho na elucidação dos significados das expressões utilizadas na linguagem corrente a partir da descrição das regras que orientam os usos das palavras, as chamadas regras gramaticais. Tais regras são padrões que estipulam o uso correto das expressões, determinando, assim, a produção de significados. Assim colocado, entende-se que “[...] a noção de gramática chama atenção para o fato de que falar uma língua é, entre outras coisas, tomar parte em uma atividade guiada por regras" (GLOCK, 1998, p. 193).

Considerando que a linguagem é uma atividade que se desenvolve segundo regras, entende-se a afirmação, em IF $\S 124$, de que: "A filosofia não deve, de modo algum, tocar no uso efetivo da linguagem; em último caso, pode apenas descrevê-lo. Pois também não pode fundamentá-lo. A filosofia deixa tudo como está" (WITTGENSTEIN, 1999, p. 67). Aqui, o "tocar no uso efetivo da linguagem" corresponde à possibilidade de se interferir diretamente na linguagem, dizendo o que pode ou não ser dito com sentido, bem como de se apresentar justificativas para tanto. Isso, segundo Wittgenstein, a filosofia não pode realizar. Não há nada de novo que a filosofia possa descobrir, cabendo-lhe apenas esclarecer aquilo que já existe, conferindo clareza no uso efetivo da linguagem a fim de desfazer confusões conceituais que, afinal, estão na origem de inúmeros problemas filosóficos.

Assim, tal como no Tractatus, Wittgenstein prescreve os limites da atividade filosófica, ora em perspectiva negativa, expressando o que a filosofia não pode realizar, ora em perspectiva positiva, apontando para aquilo que ela deve fazer, cumprindo, assim, o papel a que se destina, que é a tarefa de esclarecimento. Procedendo deste modo, a filosofia não resolve problemas filosóficos, mas, antes, os dissolve completamente. Se fosse para resolver, ela teria que apresentar uma resposta satisfatória e definitiva, o que a filosofia tradicionalmente tem feito, porém, sem obter sucesso em seus esforços. Mas como não pode resolve-los, então, só lhe cabe a dissolução, ou seja, o desfazimento total dessas questões enquanto verdadeiros problemas, que desaparecem porque são desmascarados, revelando-se, na verdade, como pseudoproblemas cuja origem repousa em confusões conceituais. Pense-se, por exemplo, nos termos metafísicos de ser e de nada, ou nos conceitos como Deus, o bom e o belo, nas concepções sobre a natureza humana e em todos os sistemas erigidos com o escopo de formular teorias a respeito dessas questões, bem como as inúmeras divergências entre os filósofos decorrentes dessas teses, em um debate infindável de opiniões. Todos esses feitos filosóficos não subsistem a uma análise do uso de tais 
palavras na linguagem ordinária, que não as emprega em seu uso metafísico, mas em seu uso efetivo. Por isso, a tarefa de esclarecimento conceitual os faz desaparecer.

À filosofia, portanto, não cabe teorizar, isto é, não cabe desenvolver sistemas de pensamento nem descobrir novas coisas. $O$ que lhe cabe é a descrição do uso das palavras guiado por regras e, por isso, caracteriza-se como uma atividade gramatical. O desenvolvimento da gramática da linguagem implica em reconhecer os seus jogos de linguagem e as regras gramaticais que informam o sentido das palavras em um determinado contexto. Sob essa perspectiva, a filosofia é terapêutica porque libera o filósofo da extenuante e doentia investigação de problemas para os quais inexistem respostas. $O$ próprio Wittgenstein concebe que sua filosofia tem por objetivo "mostrar à mosca a saída do vidro" (WITTGENSTEIN, 1999, p. 109). Presos na linguagem, os filósofos se debatem em confusões conceituais e não conseguem sair disso; para eles, Wittgenstein aponta uma saída: a filosofia como atividade de análise da gramática da linguagem. E tudo que se faz presente na linguagem submete-se a essa tarefa de esclarecimento e com ela se relaciona, inclusive a própria concepção de ser humano, como se verá a seguir.

\section{O lugar do humano: corpo e alma como unidade psicofísica}

A partir da concepção tractariana de filosofia como atividade de análise lógica da linguagem, sobre o ser humano, tomado como verdadeiro problema (evidentemente, não filosófico) somente se pode dizer com sentido sob a ótica das ciências naturais (por exemplo, os aspectos biológicos, químicos, físicos), pois essas proposições empíricas são passíveis de verificação junto aos fatos do mundo. Nesse meio, o ser humano é observável como um fato no mundo, um objeto entre os demais a ser conhecido, e tão somente isso. Consequentemente, as tentativas de dizer além disso revelam-se contrassensos que, portanto, não devem ser ditas, restando-lhes apenas serem mostradas. Para além dos aspectos que interessam à ciência, qualquer consideração sobre a natureza humana apenas pode ser mostrada, porém, jamais alçada ao patamar de um autêntico conhecimento, como presunçosamente pretendeu a tradição filosófica.

Para o primeiro Wittgenstein, o homem é visto sob duplo aspecto, a saber, como sujeito empírico (sobre o qual se pode dizer com sentido) e como sujeito metafísico (sobre o qual se pode apenas mostrar), como se depreende da leitura de TLP 5.641:

Assim, há realmente um sentido em que se pode, em filosofia, falar não psicologicamente do eu.

O eu entra na filosofia pela via de que "o mundo é meu mundo".

O eu filosófico não é o homem, não é o corpo humano, ou a alma humana, de que trata a psicologia, mas o sujeito metafísico, o limite - não uma parte - do mundo (WITTGENSTEIN, 2017, p. 231).

No texto acima, Wittgenstein sustenta que o único modo filosófico de se tratar do homem é enquanto sujeito que constitui o limite do mundo, o eu filosófico ou o sujeito metafísico. Isso porque é ele que realiza a figuração lógica do mundo na linguagem, constituindo o mundo como sua representação ("o mundo é meu mundo"), embora não se possa dizer coisa alguma, com sentido, a seu respeito ${ }^{3}$. Esse sujeito não se identifica com o homem (enquanto fato no mundo), seu corpo e sua alma, ou seja, com o sujeito empírico. Enquanto corpo, pode-se dizer

\footnotetext{
${ }^{3}$ Para tratar da diferença entre o que pode ser dito com sentido, e o que pode apenas ser mostrado, Wittgenstein reconhece que ele mesmo atenta contra os limites lógicos da linguagem que propõe no texto, sendo-lhe forçoso dizer contrassensos que se fazem necessários explicitar para a compreensão do seu trabalho filosófico. É o que consta no TLP 6.54: "Minhas proposições elucidam desta maneira: quem me entende acaba por reconhece-las como contrassensos, após ter escalado através delas - por elas - para além delas. (Deve, por assim dizer, jogar fora a escada após ter subido por ela)" (WITTGENSTEIN, 2017, p. 261).
} 
do homem por meio de proposições científicas; por sua vez, enquanto alma, a psicologia também pode tratar do humano, desde que o faça à maneira da ciência, segundo proposições passíveis de verificação entre os fatos do mundo. Em todo caso, o sujeito empírico denota a compreensão de ser humano como um mero fenômeno observável empiricamente, e é somente sob esse aspecto que se pode dizer algo a seu respeito.

A cisão entre as duas formas de compreensão do humano fica evidente também em TLP 6.423: "Da vontade como portadora do que é ético não se pode falar. E a vontade como fenômeno interessa apenas à psicologia" (WITTGENSTEIN, 2017, p. 259). A vontade do sujeito empírico, como manifestação de sua alma, pode ser investigada enquanto um fenômeno da experiência pela psicologia, mas a vontade do sujeito metafísico, que se refere à ética, bem como a estética e a religião, isto é, à dimensão dos valores, ao sentido da vida e do mundo, nada se pode dizer com sentido. Esses são, com efeitos, aspectos da humanidade aos quais somente cabem ser mostradas.

E isso é tão claro para o filósofo que, mesmo retornando à filosofia, em Conferência sobre Ética, de 1929, ele afirma que a ética é "o testemunho de uma tendência da mente humana que eu pessoalmente não posso deixar de respeitar profundamente e que nunca me ocorreria ridicularizar" (WITTGENSTEIN, 2017, p. 81). O ser humano tende a buscar um sentido para sua existência, procurando compreendê-la sob a ótica dos valores, e esse é um aspecto do humano que é profundamente respeitado por Wittgenstein, porém, reconhecendo os limites lógicos de nada se dizer quanto a isso, sob pena de se incorrer em contrassensos. Isto posto, a sua concepção de filosofia como atividade de análise lógica da linguagem, levada às últimas consequências, restringe o lugar do ser humano ao seu aspecto fenomênico, como objeto analisável empiricamente, pois sobre isso se pode dizer algo com sentido. Quanto aos outros aspectos da vida humana, nada pode dizer, restando-lhe apenas serem mostradas em sua experiência de vida.

Mas ao abandonar a análise lógica da linguagem para voltar o olhar para a linguagem ordinária, onde se apresentam os usos efetivos das expressões, a reflexão sobre o ser humano no segundo Wittgenstein ganha novo impulso a partir da busca do esclarecimento conceitual dos termos psicológicos. A psicologia, para o filósofo, não é tratada enquanto um conjunto de estudos teóricos tal como hoje se apresenta mais ou menos estruturado - a psicologia e suas divisões, conforme estudada nos currículos universitários; em vez disso, ela é compreendida como a compreensão gramatical dos estados subjetivos do homem, isto é, da sua interioridade, que se expressam na própria linguagem. É a essa atividade gramatical que a filosofia deve se dedicar para esclarecer, enfim, o que é a natureza humana. Isto posto, pode-se identificar a psicologia wittgensteiniana como uma investigação que nada mais é do que um desdobramento da sua concepção geral de filosofia, a exemplo do que já ocorrera na primeira fase do seu pensamento. $O$ que interessa para a investigação é o modo como a subjetividade se apresenta na linguagem ordinária e, assim, possibilita a compreensão dos sujeitos quanto àquilo que se passa no interior daquele que as expressa.

Antes, porém, de adentrar na compreensão wittgensteiniana, é preciso remontar brevemente a discussão filosófica que a precede. Isso porque, no cerne do problema sobre sobre o psicológico repousa uma compreensão acerca de humanidade, que é o que constitui o humano, o sujeito e sua subjetividade, que conta com uma grande tradição na filosofia e que, aqui, serve justamente para mostrar o claro contraponto que a posição de Wittgenstein representa com relação a essa mesma tradição. Com efeito, desde a Antiguidade, diversas correntes do pensamento, filosófico e também religioso, tentaram, de alguma forma, dar respostas à questão sobre o que é o ser humano, um problema tão antigo que se poderia bem considera-lo como uma das questões inauguradoras da própria filosofia. Ao lado da perplexidade sobre o mundo, o ser humano sempre se indagou sobre si mesmo, sobre sua condição, sobre sua origem e seu fim. E, 
em geral, concebeu-se como sendo um ser composto por dois elementos distintos, a saber, o corpo e a alma (entendendo-se alma enquanto mente ou espírito). Para Hacker, tal ideia é antiga e:

[...] está ligada ao nosso medo da morte, ao desejo de uma sobrevivência num mundo mais feliz, ao nosso pesar pela morte dos entes queridos e nossa esperança de reencontrálos um dia. Ela é associada a fenômenos comuns da vida humana que estão envoltos em mistério, tais como os sonhos, quando parecemos habitar um outro mundo sem conexão com nosso corpo adormecido e no qual poderíamos interagir com os mortos. Está associada também a fenômenos mais obscuros, como as experiências visionárias ou as "viagens" para fora do corpo. Além disso, porém, essa ideia está profundamente arraigada na gramática de nossas linguagens (HACKER, 2000, p. 18).

Tanto no âmbito filosófico quanto no teológico, a compreensão de homem como um ser de corpo e alma recebeu tratamento diferenciado nas várias épocas em que o problema foi colocado. Contudo, é na Modernidade que uma posição em particular ganhou notoriedade por representar um divisor de águas que, de uma forma ou de outra, influenciou os debates filosóficos pelos séculos seguintes: trata-se do racionalismo de Descartes, que radicalizou a questão da natureza do ser humano.

Para esse filósofo, o homem é essencialmente a sua alma, isto é, a sua mente, o res cogitans, a "coisa que pensa". A sua dúvida metódica levou-o a concluir, na Segunda Meditação, como primeira ideia clara e distinta, que o sujeito é pensante: "nada sou, então, a não ser uma coisa que pensa, ou seja, um espírito, um entendimento ou uma razão" (DESCARTES, 1999, p. 261). O pensamento é a substância da alma. Por sua vez, o corpo é outra substância diversa da alma, a res extensa, a "coisa extensa", cujo funcionamento é idêntico a uma máquina e obedece às leis da física. Apesar de se tratarem de coisa diferentes, corpo e alma relacionam-se porque a alma precisa do corpo. Assim, Descartes concebe a pessoa como uma alma encarnada: a alma, incorruptível, que vive em um corpo, corruptível.

Disso conclui-se que um único conhecimento certo é o que o sujeito tem de si mesmo, sendo que do seu corpo e das outras mentes, pode-se, no máximo, supor as suas existências. Sobre o corpo e os elementos físicos em geral, sempre resta a dúvida porque os sentidos não são confiáveis e podem enganar; sobre as outras mentes, o conhecimento é indireto e se dá por meio da observação, porém, permanecendo sempre algo incerto. O que na tradição filosófica convencionou-se chamar de dualismo cartesiano expõe uma concepção racionalista de ser humano, pois acentua o valor da alma (que é a própria razão) sobre o corpo, identificando o homem, basicamente, com o eu que pensa.

Porém, a respeito da origem do conhecimento, outra corrente filosófica reverteu essa situação, de maneira que, dessa vez, o corpo passou a ter proeminência como fonte de conhecimento, em radical oposição à tese racionalista, que o inferiorizava. Trata-se do empirismo, que tem em Locke e Hume os seus grandes expoentes. Na esteira desses pensadores, o conhecimento advém das experiencias sensoriais, proporcionadas pelo próprio corpo. Para Hume "o pensamento mais vivo é sempre inferior à sensação mais embaçada" (HUME, 1999, p. 35) porque o que se passa na alma (o pensamento, as ideias) não passa de cópia das sensações do corpo, onde se situa a origem das ideias. Sendo essa a opinião do filósofo, compreende-se a sua veemente crítica ao racionalismo e a qualquer posição que desconsidera a experiência como origem do conhecimento, como consta na célebre conclusão de Investigação Acerca do Entendimento Humano:

Quando percorremos as bibliotecas, persuadidos destes princípios, que destruição deveríamos fazer? Se examinarmos, por exemplo, um volume de teologia ou de metafísica escolástica e indagarmos: Contém algum raciocínio abstrato acerca da quantidade ou do número? Não. Contém algum raciocínio experimental a respeito das 
questões de fato e de existência? Não. Portanto, lançai-o ao fogo, pois não contém senão sofismas e ilusões (HUME, 1999, p. 154).

Com o empirismo, o corpo é reabilitado, porém, em linhas gerais, mantém-se o velho legado de Descartes no que diz respeito à natureza humana, posto que tanto uma quanto outra posição encerra o âmbito da subjetividade a algo interno ao sujeito da experiência. Isso porque o empirista, ao aceitar que o conhecimento provém dos dados dos sentidos, acaba por admitir que tais dados são objetos internos ao sujeito e, portanto, acessíveis apenas por introspecção. Assim, no final das contas, tal como Descartes, o empirismo reforça a tese de que o mental somente pode ser conhecido pelo próprio sujeito e que o homem está, mais uma vez, fechado em sua própria subjetividade, o solipsismo.

Como se sabe, o empirismo influenciou decisivamente o desenvolvimento da ciência moderna, da filosofia da ciência e da psicologia behaviorista que, a partir de seus pressupostos, continuaram desenvolvendo a relação mente-corpo, levando-a até as últimas consequências a ponto de, no mais das vezes, suplantarem o mental em vista do físico-corporal. Para a psicologia behaviorista que, nos dizeres de Skinner, "não é a ciência do comportamento humano, mas si, a filosofia dessa ciência" (SKINNER, 2009, p. 7), os estados mentais reduzem-se aos comportamentos que, por sua vez, são considerados como meros movimentos corporais. Outros, porém, especialmente os estudiosos da neurociência, a mente passa a ser identificada com o cérebro e, por isso, tratam o mental como neurológico que, em outras palavras, representa a redução da subjetividade às questões orgânicas, corporais. Em todo caso, longe de afastar-se da concepção de ser humano delegada pelo dualismo cartesiano, os cientistas mantêm, em linhas gerais, a mesma estrutura pensada por Descartes. Dessa vez, porém, o "dualismo mente/corpo foi substituído pelo dualismo cérebro/corpo, a substância imaterial foi substituída pela massa cinzenta" (HACKER, 2000, p. 21). Muda-se o enfoque, todavia, permanecendo inquestionada a mesma estrutura de pensamento que contrapõe corpo e alma.

Mas como Wittgenstein, segundo a sua nova concepção filosófica, compreende o problema do ser humano? Para ele, as concepções acima estão fundadas em uma ideia de natureza humana que considera equivocada. Ambos os elementos - corpo e alma - compõem uma mesma realidade, o ser humano. Diferentemente de Descartes, para o qual o homem é a res cogitans ligada a um corpo, e diferentemente dos empiristas, behavioristas e neurocientistas, para os quais o homem é o corpo, em Wittgenstein, tanto a mente (ou alma) quanto o corpo integram-se naquilo que Peter Hacker chamou como "unidade psicofísica" (HACKER, 200, p. 8). Isso significa que é o ser humano, como um todo, que pensa, sente e age no mundo; com isso, o filósofo dissolve o velho problema filosófico sobre a natureza humana, que perde seu sentido por fundar-se em uma confusão de conceitos metafísicos que estão longe do uso efetivo da linguagem ordinária.

Mas como Wittgenstein chega a essa conclusão, fazendo desaparecer o problema? Basicamente, partindo de sua concepção de filosofia como atividade de esclarecimento gramatical e, especialmente, empregando o conceito de visão panorâmica ${ }^{4}$, que denota o seu método de ver conexões entre os usos das palavras, o filósofo empenha-se no esclarecimento conceitual do que é o homem a partir da linguagem. A questão sobre o humano é antiga para Wittgenstein e remonta aos princípios do desenvolvimento do seu pensamento, o primeiro Wittgenstein, como se depreende da nota de 1914 de Cultura e Valor:

\footnotetext{
${ }^{4} \mathrm{O}$ conceito de visão panorâmica encerra o método empregado por Wittgenstein para proceder à análise gramatical da linguagem, e se encontra em IF § 122: "Uma fonte principal de nossa incompreensão é que não temos uma visão panorâmica do uso de nossas palavras. - Falta caráter panorâmico à nossa gramática. - A representação panorâmica permite a compreensão, que consiste em 'ver conexões'. Daí a importância de encontrar e inventar articulações intermediárias. O conceito de representação panorâmica é para nós de importância fundamental. Designa nossa forma de representação, o modo pelo qual vemos as coisas. (É isto uma “visão de mundo'?)" (WITTGENSTEIN, 1999, p. 67).
} 
Temos tendência para confundir a fala de um chinês com um gorgolejo inarticulado. Alguém que compreenda o chinês reconhecerá, no que ouve, a língua. Muitas vezes, não consigo, analogamente, distinguir num homem a humanidade (WITTGENSTEIN, 2000, p. 13).

Aqui se apresenta uma comparação entre o reconhecimento de um outro idioma e o reconhecimento da humanidade de um outro ser humano. No exemplo de Wittgenstein, há um salto qualitativo entre o que se entende como um gorgolejo inarticulado e o que se compreende como uma língua. Quem não conhece a língua chinesa, fica preso apenas ao seu aspecto sonoro; para ele, trata-se de sons emitidos que não lhe fazem sentido algum. Por sua vez, quem conhece o idioma reconhece-o como tal e pode até mesmo participar do diálogo; os sons ali emitidos fazem-lhe sentido. De modo semelhante, há algo que permite dar um salto qualitativo também entre o que se tem diante de si (um ser humano qualquer) e a sua humanidade, que pode ser distinguida nele, ainda que nem sempre isso seja fácil de realizar, como reconhece o filósofo.

Mas, então, como "distinguir num homem a humanidade"? A humanidade, compreendida como aquilo que faz a pessoa ser um humano, não é, por certo, algo interno ao sujeito, como se estivesse escondido, acessível apenas a ele, como se pode compreender a partir de Descartes e dos empiristas. Porém, tampouco se identifica com o movimento corporal ou com o funcionamento do órgão cerebral, como sustentam os behavioristas e os neurocientistas. Longe desses extremos, a proposta de Wittgenstein, que possibilita reconhecer a humanidade do outro, passa pela conciliação entre corpo e alma, dois conceitos tradicionalmente colocados em lados opostos pela filosofia. $O$ filósofo põe-se, mais uma vez, em sentido contrário à tradição filosófica, contudo, não assumindo uma ou outra posição, mas destruindo de vez a própria estrutura do problema, mostrando a falta de sentido da própria dicotomia. A esse respeito, a seção IV da Parte II de IF (a Parte II é atualmente concebida como escrito à parte, intitulado como Filosofia da Psicologia - Um Fragmento ${ }^{5}$ ), esclarece o seguinte:

\footnotetext{
"Creio que ele sofre". - Creio também que ele não é nenhum autômato?

Apenas com repugnância poderia pronunciar a palavra em ambos os contextos.

(Ou será assim: creio que ele sofre; estou certo de que não é um autômato? Absurdo!).

Imagine que eu diga de um amigo: "ele não é um autômato". - O que é comunicado aqui e para quem isto seria uma comunicação? Para um homem que encontra outro em circunstâncias habituais? O que poderia isto comunicar-lhe" (No máximo que este sempre se comporta como um ser humano e não se comporta algumas vezes como uma máquina).

"Creio que ele é um autômato" não tem assim, sem mais, nenhum sentido.

Minha atitude em relação a ele é uma atitude com relação à alma. Não sou da opinião de que ele tenha uma alma.

$[\ldots]$

O corpo humano é a melhor imagem da alma humana (WITTGENSTEIN, 1999, p. 168).
}

O trecho traz à tona o que pode ser compreendido como uma regra gramatical que orienta o uso que se faz da linguagem, manifesta pela expressão "atitude com relação a uma alma". Essa regra, assumida pelas atividades linguísticas, permite o reconhecimento do outro como ser humano. Na linguagem cotidiana, é possível distinguir claramente que os homens agem, em relação aos seus semelhantes, de maneira diferente com que agem em relação às coisas ao seu redor, inclusive, com um autômato que, mesmo virtualmente dispondo de inteligência artificial para imitar práticas humanas, ainda assim, não é reconhecido como ser humano. Portanto, a atitude com relação à alma denota o comportamento que os sujeitos assumem diante de outros

\footnotetext{
${ }^{5}$ A partir da quarta edição inglesa de IF, publicada em 2009, os editores Peter Hacker e Joachim Schulte eliminaram a divisão da obra em duas partes, tal como até então fora tradicionalmente concebida. Assim, a Parte II passou a ser considerado um texto a parte, sob o título Filosofia da Psicologia - Um Fragmento. A tradução brasileira utilizada neste texto segue as edições anteriores e, por isso, encontra-se dividida em partes I e II.
} 
seres humanos, a interação que ocorre entre eles que não se compara, sequer, à relação que se tem com as inteligências artificiais, e que está pressuposta na linguagem. Essa atitude diferenciada constitui uma crença de que as outras pessoas são seres humanos, sujeitos da linguagem, e tal convicção não é passível de questionamento nem de justificação, sob pena de se estar incorrendo em um absurdo.

Para Wittgenstein, soa repugnante problematizar se uma pessoa é ou não um autômato. No fluxo da vida, os seres humanos não levantam esse tipo de objeção porque nela não se há qualquer sentido. A filosofia tradicional, ela sim, inclina-se a levantar problemas onde, no uso efetivo da linguagem, eles não existem. Mas basta um olhar atento para a linguagem ordinária (e essa é a função da filosofia como atividade de análise gramatical) para constatar que não é assim que os sujeitos se comunicam; ao contrário, as pessoas se expressam umas às outras reconhecendo no outro a sua humanidade, sem separar corpo e alma. E isso é válido, inclusive, quando as atitudes visam causar danos a indivíduos particulares ou grupos específicos, já que qualquer tentativa de desumanização dos sujeitos (como as práticas de escravidão, de genocídio, de perseguições etc) pressupõe identifica-los como seres humanos. Nesses casos funestos que, infelizmente, a história é testemunha, o que se verifica como primeiro passo é a descaracterização do humano das pessoas, a fim de reduzi-las ao estatuto de não-humanos para justificar ideologicamente esses procedimentos totalitários e fascistas.

Mas o que faz com que a atitude para com um ser humano seja diferente da atitude que se pode ter para com uma pedra, por exemplo, mas principalmente, com os autômatos, face ao acentuado desenvolvimento tecnológico das inteligências artificias? No final do excerto acima, Wittgenstein traz luz à relação corpo-alma quando afirma que o corpo é a melhor imagem da alma. A crença na humanidade dos outros, subjacente à atitude para com a alma, supõe a superação de uma clássica dicotomia da filosofia, a relação corpo-alma. A alma (que equivale à interioridade do sujeito, a sua subjetividade) não está escondida dentro da própria pessoa, acessível exclusivamente a esta, mas se dá no corpo do sujeito, em seu comportamento que manifesta o que é o ser humano. É por isso que se pode afirmar, em terceira pessoa, que se sabe que alguém sente dores porque a dor, embora sentida apenas pelo sujeito, é expressa por ele pelo modo como se comporta, tornando-a manifesta nas expressões de seu próprio corpo. $\mathrm{O}$ "saber", aqui, não é um conhecimento do tipo que se pode ter a respeito dos objetos físicos, afinal, a dor não é um objeto físico. Mas, como um termo psicológico, expressa o reconhecimento de que a pessoa manifesta suas dores, em seus gestos, em seu rosto, em seu comportamento.

Assim, não se diz propriamente que o corpo sente dores (ou em sentido figurado, que a alma sente dores), mas que a pessoa, como um todo, sente dores. É como corpo e alma, ou melhor, como uma unidade entre o interno e o externo, a animalidade encarnada, que o sujeito se comporta no mundo, revelando a sua humanidade e se fazendo reconhecer nessa mesma condição por seus semelhantes. Em IF $§ 420$ há o seguinte esclarecimento a esse respeito:

Mas não posso imaginar que os homens que me rodeiam são autômatos, não tem consciência, mesmo que seu modo de agir seja o mesmo de sempre? - Se eu agora, sozinho em meu quarto, me represento isso, então vejo as pessoas com olhar fixo (mais ou menos como em transe) seguirem seus afazeres - a ideia é talvez um pouco incomum. Mas tente uma vez, no trânsito costumeiro, por exemplo, na rua, fixar-se nesta ideia! Diga, por exemplo, a si mesmo: "As crianças ali são meros autômatos; toda a sua vivacidade é meramente automática". E estas palavras, ou lhe dirão absolutamente nada, ou você nada produzirá em si mesmo algo como uma espécie de sentimento sinistro ou algo semelhante.

Ver um homem vivo como autômato é análogo a ver alguma figura como caso limite ou variação de uma outra, por exemplo, uma armação em cruz de vidraça como suástica (WITTGENSTEIN, 1999, p. 127-128). 
O exemplo de que trata o filósofo sobre a vivacidade das crianças serve para ilustrar que seus corpos manifestam ações que se supõem serem de humanos. Assim, avançando um pouco mais, tem-se, em última análise, que a humanidade das pessoas se expressa em seu agir. É por meio do comportamento humano que o seu interno (a alma, a subjetividade) e o seu externo (o corpo) encontram-se conectados e fazem-se presentes no mundo: "[...] quando se vê o comportamento de um ser vivo, vê-se sua alma" (WITTGENSTEIN, 1999, p. 177). O comportamento fornece critérios para se dizer a respeito do que se passa no interior do sujeito, apresentando evidências suficientes disso.

Voltando-se para as ações humanas, cumpre notar uma importante distinção efetuada por Wittgenstein, a de que elas não se confundem com meros movimentos corporais porque, diferente destes, podem ser voluntárias e intencionais. Quanto à voluntariedade da ação, o que a distingue de um movimento qualquer "é sua relação com padrões mais amplos, a maneira como eles se conectam com outros elementos em nossas vidas" (JOHNSTON, 2014, p. 177). O contexto em torno da ação possibilita julgá-la como voluntária porque oferece dados que funcionam como padrões de comportamentos mais ou menos conhecidos. De acordo com o parágrafo 594 de Fichas (Zettel): "[...] existe uma ação combinada de movimentos, palavras, expressões faciais, assim como de manifestações de relutância ou de boa-vontade, que são características dos movimentos voluntários de um ser humano normal" (WITTGENSTEIN, 1989, p. 133). Todos esses movimentos possibilitam inferir a voluntariedade da ação porque são atitudes comuns do comportamento humano, manifestando um modo de agir comum de qualquer humano. É por isso que se pode pensar que um robô possa se comportar como um ser humano, mas não o contrário.

Por sua vez, a intencionalidade da ação remete à intenção do agente, isto é, a razão pelo qual ele age. Pela intenção distingue-se uma ação voluntária de uma ação não-voluntária. No parágrafo 805 do Livro I de Observações sobre a Filosofia da Psicologia a relação entre voluntariedade e intenção torna-se evidente: "A voluntariedade está conectada ao caráter proposital [Absichtlichkeit]. E por conseguinte também à decisão. Não se decide ter um ataque de angina e então se o tem" (WITTGENSTEIN, 2008, p. 174). Quando age, o sujeito mostra o que intenciona fazer. É por isso que se pode dizer, de acordo com Johnston, que as ações voluntárias “[...] são 'ações pensadas': comportar-se desse modo é comportar-se como um ser humano normal faria, e esse comportamento é caracterizado pela intencionalidade e propósito" (JOHNSTON, 2014, p. 181). Dessa forma, qualquer pessoa pode ser indagada pela ação que praticou e expor as razões que a levaram a agir dessa maneira, expressando, assim, a sua intenção. Assim, a intencionalidade remete às justificativas da própria ação, que somente um ser humano é capaz de dar.

É evidente que nem toda ação, como dito acima, é voluntária. Há situações em que as pessoas são forçadas a agirem por coação, o que limita, ou até mesmo anula completamente a intencionalidade do agente no caso específico. Todavia, essas ações não anulam a sua humanidade; antes, reconhece-se que a privação da vontade é, justamente, uma medida excepcional que atenta contra a humanidade do sujeito, o que serve, mais uma vez, para confirmar que o reconhecimento da humanidade do outro é pressuposta. Desse modo, permanece válida a ideia de que são o agir, o pensar e o sentir que humanizam os indivíduos e possibilitam o reconhecimento desse estatuto por seus pares. Não há subjetividade que não se possa expressar, e essa expressão se realiza na linguagem. E é esse o uso efetivo do conceito de ser humano que as pessoas articulam em suas atividades linguísticas: o homem se constitui e se faz reconhecer enquanto humano por meio da linguagem. 


\section{Considerações finais}

As considerações aqui trazem à luz a contribuição original de Wittgenstein de refletir a humanidade em termos de um todo psicofísico que se expressa pela linguagem. A clássica separação corpo-alma perde todo o sentido porque, na linguagem ordinária, não há divisão no homem, mas unidade. Wittgenstein não nega a existência da interioridade do sujeito, mas tão somente a radical separação existente entre o interno e o externo, que pretende privar o acesso ao interno. Na verdade, essa dicotomia é um pseudoproblema que se dissipa graças à sua conceção de filosofia enquanto atividade gramatical. E é a partir da gramática do uso do conceito de ser humano na linguagem ordinária que se pode pensar o sujeito por inteiro, o que possibilita identificar no outro a mesma natureza de que dispõe o próprio sujeito. Dessa forma, depreende-se que não é a alma que pensa nem é o corpo que sente, mas é o ser humano que pensa, sente e age no mundo. É como tal integração, manifesta no comportamento humano, que supera a divisão entre o externo e o interno, entre o corpo e a alma, que se concebe a natureza humana a partir de Wittgenstein. 


\section{Referências}

DESCARTES, René. Meditações. Trad. Enrico Corvisieri. Col. Os Pensadores. São Paulo: Nova Cultural, 1999.

GLOCK, Hans-Johan. Dicionário Wittgenstein. Trad. Helena Martins. Rio de Janeiro: Jorge Zahar, 1998.

HACKER, P. M. S. Wittgenstein: sobre a natureza humana. Trad. João Vergílio Gallenari Cuter. São Paulo: Editora UNESP, 2000.

HUME, David. Investigação acerca do Entendimento Humano. Trad. Anoar Aiex. Col. Os Pensadores. São Paulo: Nova Cultural, 1999.

JOHNSTON, Paul. Wittgenstein and Moral Philosophy. New York: Routledge, 1989.

SKINNER, B. F. Sobre o Behaviorismo. 15 ed. Trad. Maria da Penha Villalobos. São Paulo: Cultrix, 2009.

WITTGEnSTEIN, Ludwig. Conferência Sobre Ética. Trad. António Marques. Lisboa: Calouste Gulbenkian, 2017.

WITTGENSTEIN, Ludwig. Cultura e Valor. Trad. Jorge Mendes. Lisboa: Edições 70, 2000.

WITTGENSTEIN, Ludwig. Fichas (Zettel). Trad. Ana Berhan da Costa. Lisboa: Edições 70, 1989.

WITTGEnSTEIN, Ludwig. Investigações Filosóficas. Trad. José Carlos Bruni. São Paulo: Nova Cultural, 1999.

WITTGENSTEIN, Ludwig. Observações sobre a Filosofia da Psicologia. Trad. Ricardo Hermann Ploch Machado. Aparecida: Ideias e Letras, 2008.

Autor(a) para correspondência / Corresponding author: Marcelo Ferreira Ribas. marceloferreiraribas@hotmail.com 